\title{
AVALIAÇÃO DA PRODUÇÃO DE BIOSSURFACTANTE EMPREGANDO FUNGOS E GLICEROL COMO SUBSTRATO
}

\author{
J. M. PASSONE ${ }^{1}$, N. M.S FERNANDES ${ }^{1}$, V. L. CARDOSO $^{1}$ e P. A. VIEIRA ${ }^{1}$ \\ ${ }^{1}$ Universidade Federal de Uberlândia, Faculdade de Engenharia Química \\ E-mail para contato: juliapassone@gmail.com
}

\begin{abstract}
RESUMO - Este estudo avaliou o desempenho de 03 tipos de fungos coletados e isolados de ambientes do cerrado do Triângulo Mineiro sendo denominados de C18, C35 e C40. Estes fungos foram previamente selecionados em testes preliminares de fermentação dentre 14 tipos de fungos, os quais apresentaram maior potencial para produzir biossurfactante. Visando selecionar o microorganismo, bem como o melhor tempo de processo e concentração de glicerol, condições estas capazes de promover maior produção de biosurfactantes os experimentos foram realizados em frascos erlenmyer de $500 \mathrm{~mL}$ contendo 100 $\mathrm{mL}$ de meio de cultivo e variadas concentrações de glicerol $(1,1,5,2,5,5,0$ e $10 \%$ v/v) sob agitação a $110 \mathrm{rpm}$ a $30 \pm 3^{\circ} \mathrm{C}$ em 48 e 72 horas de processo. Os resultados mostraram, que dentre as condições avaliadas as que promoveram maior produção de biossurfactante foi empregando a cultura C35 na concentração de glicerol de $1,5 \% \mathrm{v} / \mathrm{v}$ em $48 \mathrm{~h}$ de processo. Estas condições serão empregadas em trabalhos futuros, visando a otimização das condições de produção de biossurfactante.
\end{abstract}

\section{INTRODUÇÃO}

Em setembro de 2014, foi decretada e sancionada a lei $\mathrm{N}^{\circ} 13.033$ onde foram estabelecidos os percentuais de adição obrigatória de biodiesel ao óleo diesel comercializado ao consumidor final de: $6 \%$ a partir de $1^{\circ}$ de julho de 2014 e de $7 \%$ a partir de $1^{\circ}$ de novembro de $2014 \quad$ (http://www.planalto.gov.br/ccivil_03/_Ato20112014/2014/Lei/L13033.htm).

Com a crescente produção de biocombustíveis, é esperada uma grande disponibilidade de glicerol, pois este é um subproduto abundante da produção do biodiesel. A utilização de óleos vegetais, como o de mamona e de canola para a produção do biodiesel gera para cada 10 $\mathrm{kg}$ de biodiesel, $1 \mathrm{~kg}$ de glicerol (Yazdani e Gonzales, 2007). Isto significou uma produção atual de 200 milhões de litros de glicerina por ano no Brasil.

A conversão do glicerol em outras moléculas é um desafio e uma alternativa para reduzir os custos da produção do biodiesel (Papanikolaou et al., 2011). Todavia, novas aplicações estão sendo procuradas para grandes volumes de glicerol, pois este, não pode ser utilizado para uso direto em alimentos e cosméticos sem um processo de limpeza e refino (Pachauri e He, 2006).

Vários estudos científicos vêm buscando alternativas para a utilização do glicerol bruto advindo do processamento do biodiesel. Chatzifragkou e colaboradores (2011) testaram 


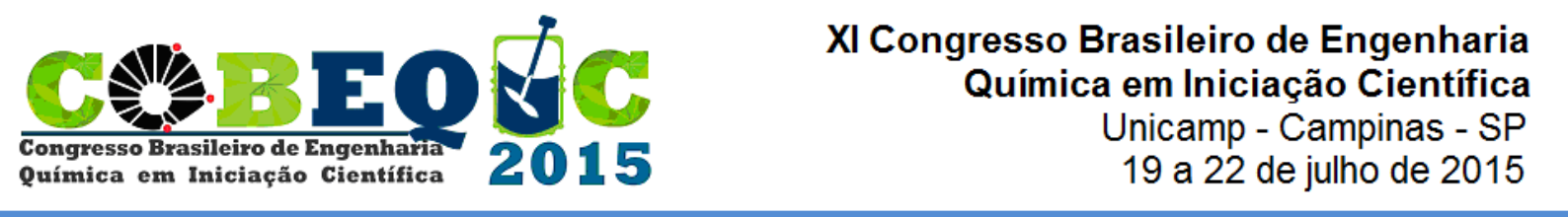

quinze micro-organismos eucarióticos quanto à sua capacidade para assimilar glicerol bruto e convertê-lo em produtos metabólicos de alto valor agregado. Dos Santos (2011) avaliou a produção de biossurfatante a partir de glicerol, empregando a Pseudomonas aeruginosa EQ 109 isolada de ambiente contaminado com óleo cru e os resultados indicaram a possível formação de um raminolipídeo estável em diferentes temperaturas.

Neste contexto, este trabalho aparece no cenário científico buscando condições de processo: tempo de processo e concentração de glicerol, bem como linhagens fungícas que proporcionem maiores produções de biossurfactantes, empregando glicerol como fonte alternativa de carbono de menor custo.

\section{MATERIAIS E MÉTODOS}

\subsection{Microrganismos}

Os micro-organismos avaliados neste estudo foram previamente selecionados de um total de 14 tipos de fungos coletados e isolados de árvores, frutos e cascas do cerrado do Triângulo Mineiro, mantidos no do banco de cultura do Núcleo de Bioquímica da Faculdade de Engenharia Química da Universidade Federal de Uberlândia. Tais micro-organismos selecionados foram denominados de C18, C35 e C40. Estes apresentaram em testes preliminares de fermentação potencialidade em produzir biossurfactantes, sendo mantidos em meio de cultura CZAPECK (composição: glicose $20 \mathrm{~g} / \mathrm{L}$, nitrato de sódio $2 \mathrm{~g} / \mathrm{L}$, Fosfato dibásico de potássio $1 \mathrm{~g} / \mathrm{L}$, Sulfato de magnésio $0,5 \mathrm{~g} / \mathrm{L}$, Sulfato ferroso 0,01 g/L, Cloreto de potássio $0,50 \mathrm{~g} / \mathrm{L}$ e Ágar $20 \mathrm{~g} / \mathrm{L}$ ) em placas de petri, incubados por $48 \mathrm{~h}$ a $30 \pm 1^{\circ} \mathrm{C}$ e posteriormente armazenados sob refrigeração.

\subsection{Fonte de Carbono}

Utilizou-se como substrato glicerol comercial (Vetec, Rio de Janeiro, Brasil) com pureza de $99,5 \%$.

\subsection{Preparo do Inóculo: Pré-Inóculo}

Após crescimento dos micro-organismos em placas Petri, estes foram transferidos para Erlenmeyers de capacidade de $250 \mathrm{~mL}$ contendo $100 \mathrm{~mL}$ do meio de cultura CZAPECK líquido (sem ágar) previamente esterilizado à temperatura de $121^{\circ} \mathrm{C}$ por 20 minutos e deixando fermentar por $48 \mathrm{~h}$ a temperatura ambiente.

\subsection{Seleção das Condições de Processo para Produção de Biossurfactante}

Para a escolha do tempo de processo, da concentração de glicerol e do fungo produtor de biossurfactante, os experimentos foram realizados em frascos erlenmyer de $500 \mathrm{~mL}$ contendo $100 \mathrm{~mL}$ de meio de cultivo (composição em $\mathrm{g} / \mathrm{L}: \mathrm{K}_{2} \mathrm{HPO}_{4}=0,5 ; \mathrm{KH}_{2} \mathrm{PO}_{4}=1$,4; $\mathrm{NH}_{4} \mathrm{NO}_{3}=1,0 ; \mathrm{MgSO}_{4} \cdot 7 \mathrm{H}_{2} \mathrm{O}=0,1 ; \mathrm{CaCl}_{2} .2 \mathrm{H}_{2} \mathrm{O}=0,02 ; \mathrm{MnSO}_{4} . \mathrm{H}_{2} \mathrm{O}=0,03$; Extrato de levedo= $2,0)$. Este meio foi esterilizado a $121^{\circ} \mathrm{C}$ por 20 minutos. Variadas concentrações de glicerol foram testadas $(1,1,5,2,5,5,0$ e $10,0 \% \mathrm{v} / \mathrm{v})$ em $20 \mathrm{ml}$ de inóculo (previamente preparado, item 2.3) sob agitação a $110 \mathrm{rpm}$ a temperatura ambiente $30 \pm 3^{\circ} \mathrm{C}$ por tempos variados de processo de 48 e $72 \mathrm{~h}$. 
Os resultados acompanhados foram: índice de emulsificação e tensão superficial.

\subsection{Análises Quantitativas}

Tensão superficial: A tensão superficial foi medida em tensiômetro completo. As análises foram realizadas a $25^{\circ} \mathrm{C} \pm 1{ }^{\circ} \mathrm{C}$.

Índice de emulsificação ou atividade emulsificante: O líquido fermentado após separação por centrifugação à $12500 \mathrm{rpm}$ (corresponde a um campo centrífugo relativo de $18900 \mathrm{~g}$ ) para remoção das células livre de células foi utilizado para determinar o índice de emulsificação (IE) pelo método o mesmo adotado por Lima (2007).

\section{RESULTADOS E DISCUSSÃO}

A Tabela 1 apresenta os resultados obtidos de índices de emulsificação ao se empregar diferentes concentrações de glicerol para as culturas C18, C35 e C40, após 48 e 72 h de fermentação.

Tabela 1 - Índices de Emulsificação obtidos nos tempos de $48 \mathrm{~h}$ e $72 \mathrm{~h}$ de processo empregando os fungos C18, C35 e C40.

\begin{tabular}{|c|c|c|c|c|c|c|}
\hline \multicolumn{7}{|c|}{ Índice de Emulsificação (\%) } \\
\hline & $\mathrm{C} 18$ & & $\mathrm{C} 35$ & & $\mathrm{C} 40$ & \\
\hline $\begin{array}{c}\text { Concentração } \\
\text { de Glicerol } \\
(\% \mathrm{v} / \mathrm{v})\end{array}$ & $48 \mathrm{~h}$ & $72 \mathrm{~h}$ & $48 \mathrm{~h}$ & $72 \mathrm{~h}$ & $48 \mathrm{~h}$ & $72 \mathrm{~h}$ \\
\hline 1,0 & 64,3 & 64,3 & 64,3 & 38,6 & 68,6 & 67,1 \\
\hline 1,5 & 52,8 & 57,1 & 71,4 & 45,7 & 64,3 & 68,6 \\
\hline 2,5 & 64,3 & 71,4 & 65,7 & 71,4 & 64,3 & 55,7 \\
\hline 5,0 & 61,4 & 57,1 & 57,1 & 64,3 & 55,7 & 68,6 \\
\hline 10 & 57,1 & 57,1 & 28,6 & 45,7 & 58,6 & 60,3 \\
\hline
\end{tabular}

Pode-se observar por meio da Tabela 1, que o índice de emulsificação variou de 28,6 a $71,4 \%$. Além disso, verifica-se que o aumento do tempo de processo foi favorável para o aumento do índice de emulsificação para as seguintes condições: concentrações de glicerol de 1,5 e $2,5 \% \mathrm{v} / \mathrm{v}$ empregando a cultura $\mathrm{C} 18$, concentrações de glicerol de 2,5, 5,0 e 10,0 \% v/v empregando a cultura C35 e concentrações de glicerol de 1,5, 5,0 e 10,0 \% v/v empregando a cultura $\mathrm{C} 40$, respectivamente. $\mathrm{O}$ maior índice de emulsificação foi verificado para a condição

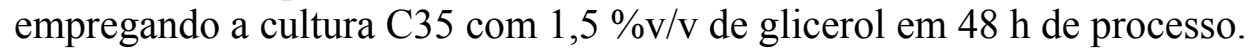
avaliadas.

A Figura 1 mostra os resultados obtidos de tensão superficial (TS) para as condições 


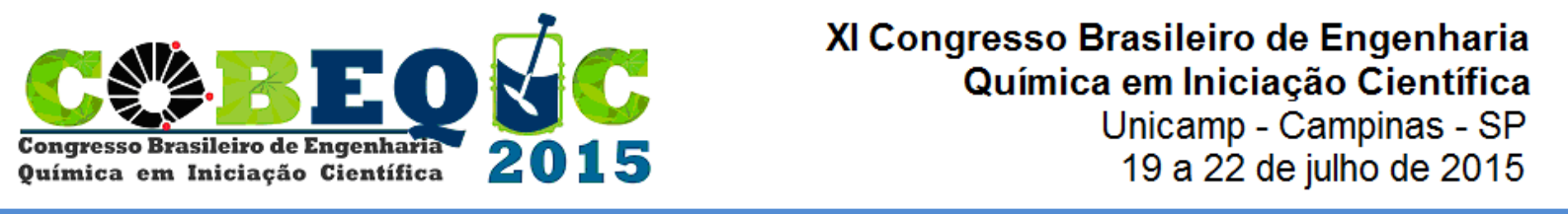

Figura 1- Tensão Superficial nos tempos de $48 \mathrm{~h}$ e $72 \mathrm{~h}$ de processo empregando os fungos $\mathrm{C} 18, \mathrm{C} 35$ e $\mathrm{C} 40$.
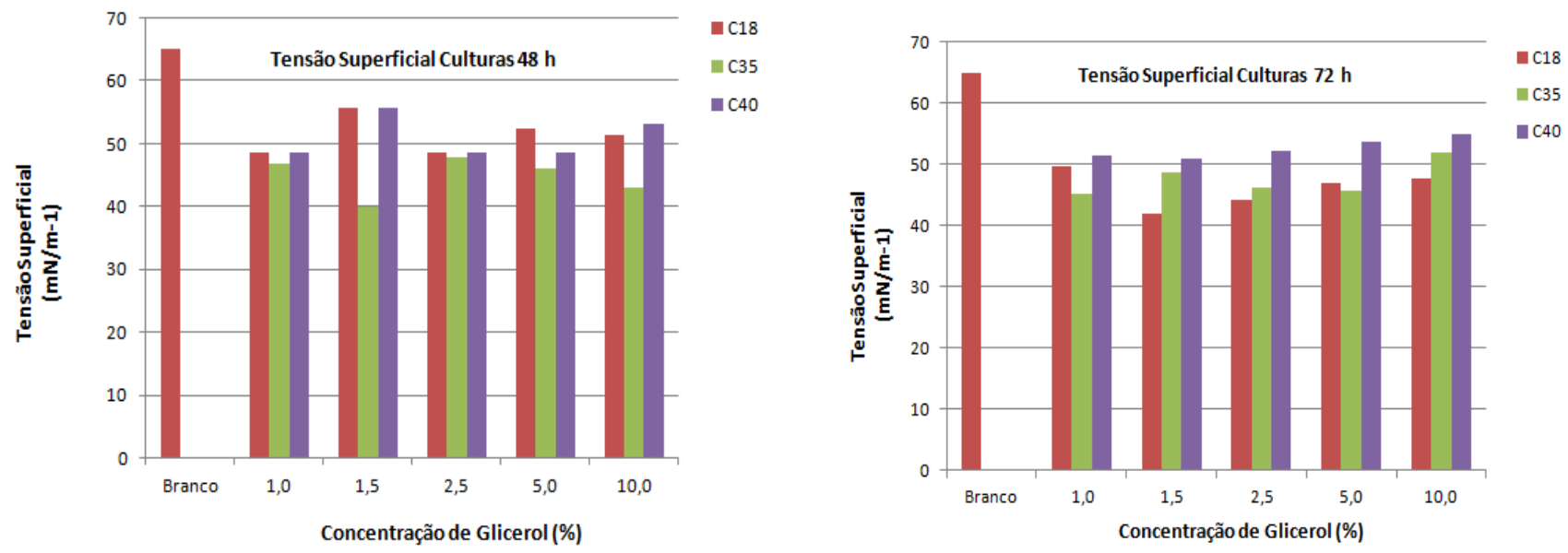

Verifica-se por meio da Figura 1, que o aumento do tempo de processo para $72 \mathrm{~h}$ foi importante para aumentar efetivamente a produção de biossurfactante para a condição empregando a cultura C18 na concentração de 1,5\% (v/v) de glicerol apresentando menor valor de TS. Além disso, verifica-se que a condição empregando a cultura C35 com 1,5\%v/v de glicerol em $48 \mathrm{~h}$ de processo promoveu a maior produção efetiva de biossurfactante, apresentando o menor valor de tensão superficial de $40 \mathrm{mN} / \mathrm{m}^{-1}$.

A redução da tensão superficial de um meio aquoso é um indicativo de produção de tensoativo. Quanto maior a quantidade de surfactante, menor a tensão superficial (Lima, 2007).

\section{CONCLUSÃO}

Pode-se observar pelos resultados apresentados, que as condições que promoveram maior produção de biossurfactante foi empregando a cultura C35 na concentração de glicerol de $1,5 \% \mathrm{v} / \mathrm{v}$ em $48 \mathrm{~h}$ de processo. Estas condições serão empregadas nas próximas etapas de estudos, visando a otimização das condições de produção de biossurfactante.

\section{REFERÊNCIAS}

Chatzifragkou, A., Makri A., Belka A., Bellou S., Mavrou M., Mastoridou M., Mystrioti P., Onjaro G., Aggelis G., Papanikolaou S., 2011. Biotechnological Conversions of Biodiesel Derived Waste Glycerol by Yeast and Fungal Species. 36, 1097-1108.

Lima, C. J. B., 2007. Produção de Biossurfactante por Pseudomonas aeruginosa Empregando Óleo de Soja Residual. Tese de Doutorado. Faculdade de Engenharia Química. Universidade Federal de Uberlândia.

Papanikolau, S., Chatzifragkou, A., Dietz, D., Doulgeraki, A.I., Nychas, G.J.E., Zeng, A., 2011. Production of 1,3-propanediol by Clostridium butyricum growing on biodieselderived crude glycerol through a non-sterilized fermentation process. Biotechnological products and process engeneering. 101-112. 
Rossi, D. M., Ayub, M. A. Z., 2009. Produção Biotecnológica de 1,3- Propanodiol e Hidrogênio a Partir de Glicerol Residual Oriundo da Síntese Química de Biodiesel. VIIIOktoberforum- Programa de Pós Graduação em Engenharia Química. Universidade Federal do Rio Grande do Sul-RS.

Santos, F. P. B. Dos., 2011. Produção de Biossurfatante por Pseudomonas aeruginosa EQ 109 a Partir de Glicerol. Tese de Doutorado. Escola de Química. Universidade Federal do Rio de Janeiro. Rio de Janeiro-RJ.

Yazdani, S. S., Gonzalez, R., 2007. Anaerobic fermentation of glycerol: a path economic viability for the biofuels industry. Current Opinion in Biotech. 18, 213-219.

\section{AGRADECIMENTOS}

Os autores agradecem ao apoio financeiro da Fundação de Amparo à Pesquisa do Estado de Minas Gerais - FAPEMIG, CAPES e CNPq - Brasil e à Faculdade de Engenharia Química (FEQUI-UFU). 